\title{
Electromagnetic Compatibility Studies within Smart Grid Automated Substations
}

\author{
A. I. Tarmizi \\ University of Southampton, UK \\ Universiti Teknikal Malaysia Melaka \\ ait1g12@ecs.soton.ac.uk
}

\author{
Mihai D. Rotaru \\ University of Southampton, UK \\ mr@ecs.soton.ac.uk
}

\author{
Jan K. Sykulski \\ University of Southampton, UK \\ jks@soton.ac.uk
}

\begin{abstract}
Switching, fault currents, lightning and other transient phenomena produce electromagnetic fields that may disturb the normal functioning of a high voltage power substation. With the advent of the 'smart grid' - where electronic control and communication equipment are integrated within the substation - understanding of the electromagnetic environment and the resulting interferences is becoming very important. This paper uses an example of a particular $400 / 220 \mathrm{kV}$ substation in Romania to analyse its behaviour from the point of view of transient stability and faults. The results of the transient analysis in terms of currents will then be used to excite an electromagnetic model with the aim to predict the field distribution within the substation during the transient. These results will in turn be used to identify the EMI 'hot spots' within the substation.
\end{abstract}

Index Terms-- EMI, fault analysis, smart grid, substation, transient stability.

\section{INTRODUCTION}

Power systems need to operate under increasingly complex conditions and situations. The recent large implementation and penetration of renewable generation and demand have introduced new challenges to the operation of the electric grid. To cope with these challenging conditions the overall system's operation requires new and innovative approaches in order to enhance the performances of the power grid. One of the novel ways is the concept of a smart grid. Sensing nodes, communication networks and information systems are embedded and integrated into the power network to create a 'smart' grid that is able to manage almost autonomously all operating conditions by itself. A smart grid is a power system that enables real-time communication and control between the consumer and the utility such that the energy usage is optimised. It is able to consider different aspects, such as cost and technical and environmental constrains, when providing an optimum power supply to the customer. To operate in such a mode the smart grid will utilise digital information technology to create a more efficient, reliable and responsive network that is flexible. Communication within a smart grid will not be limited to that between the consumer and the utility only, but will include channels between digital relays, so that information could be exchanged between relays without necessarily involving the control centre. This type of communication networking will provide a self-managing capability that will allow the smart grid to develop different strategies in the protection and control of the system. The smart grid architecture aims to provide overall power network monitoring, create control strategies to maintain the system performance and security and reduce the cost of operation, maintenance and system availability planning. The control built within a smart grid will allow the flexibility to handle distributed resources, stochastic demand, to adapt to new conditions of operation and to respond in an optimal manner to smart appliances connected to the grid [1-7].

Consequently, a smart grid has the potential to improve the efficiency and reliability of the power delivery; however, due to its increased complexity and dependence on technologies that were not previously part of the power grid, the smart grid may be susceptible to factors that will affect negatively its normal functioning. Some of these factors result from Electromagnetic Interference (EMI). All power grid devices are exposed to electromagnetic (EM) fields of natural or manmade origin, radiated directly into devices or conducted via the power, signal or ground connections. A smart grid may contain a large number of data communication channels, in support of applications with divergent functions, which can all be degraded by electromagnetic interference. These functions have different reliability requirements, correlating with different levels of data flow reliability, and may require different radiated and conducted immunity levels [8].

Our research aims to develop the understanding of the electromagnetic environment in which the smart grid will function and identify possible EMC/EMI issues. EMC has to be considered to ensure continuous reliable operation in many locations where the smart grid equipment may operate. Components and devices in the smart grid system are subjected to a wide range of conducted and radiated noise sources that are disruptive to all electronic equipment.

The substations in a power network afford one of the most severe electromagnetic environments where the equipment of a smart grid has to function correctly and reliably. The term "substation" describes the physical location in the grid that contains transformers, circuit breakers, capacitor banks, voltage regulators, sensors, protective relays and other equipment necessary for controlling and distributing electric power. Substations provide critical interconnections and are located throughout the grid for generation (as part of a power plant), transmission and distribution systems, and for distributed generation (DG) projects. The primary voltages at these substations will vary depending on the location. These substations can be as simple as a few circuit breakers or include complex systems covering large areas. For the purpose of this EMI discussion, the substation EM environment is defined as an area of high EM fields, including transients from switching that are higher than those found in other portions of the distribution system. The 
physical substation environment is generally the area bounded by a grounded fence around the substation yard and/or building and the area extending a few meters outside the fence [8]. Substations are very complex in their protection and control schemes.

The microprocessor-based protective relays have recently been replacing electromechanical ones, especially at major substations. These devices not only offer protection, but also act as intelligent electronic devices (IEDs) that perform control functions, metering, substation automation, etc. The communication between these devices is currently serial using copper wires; the trend, however, is to replace wires between devices with Station Bus technology using Ethernet IP connectivity over fibre-optic cable and to network communication protocols for new or expanded installations. The power line carrier (PLC) transmitters/receivers, microwave and optical fibre communication multiplexers used in conjunction with protective relays to provide pilot protection schemes are now IEDs.

In this work, we have analysed - through simulation - a high voltage substation. The aim was to build a simulation model capable of simulating the transient processes and phenomena that can produce EMC noise that may potentially affect the smart grid equipment within the substation. This paper has analysed the behaviour of a $400 / 220 \mathrm{kv}$ high voltage substation in Romania called Rosiori for the transient stability and fault analysis. The results of the transient analysis in terms of currents will be used as excitation in an electromagnetic model of the substation with the aim to find electromagnetic field distribution. These results will then be used to identify EMI 'hot spots' within the substation. The placement of the sensitive control electronic equipment will be optimized so that the hot spots are avoided, hence reducing the danger of equipment malfunction.

\section{SMART GRID AUTOMATED SUBSTATION}

In substations the power grid equipment is installed, such as transformers, circuit breakers, capacitor banks, voltage regulator protection relays, sensors and control equipment for power system operation. Currently, the majority of this conventional equipment relies on mechanical components. There is a trend, however, to replace electromechanically actuated relays with microprocessor based relays, especially in major substations. These new relays can act as intelligent electronic devices and perform extra duties, such as control and metering.

Substation automation systems are categorised into three hierarchical levels, which are found in most implementations as physical levels (Fig. 1) [8]. The levels are referred to as: the process level, the bay level and the station level. The process level refers to the individual power system equipment in the substation represented by the process interface, e.g. circuit breakers, transformers, electronic current transformers (ECT), electronic voltage transformers (EVT) and merging units. The bay level consists of bay protection and control IEDs hosting the related functions. The station level consists typically of the substation computer with central functions, human machine interface (HMI) and the gateway to the network control centre. The station and bay levels are connected by the station bus. The bay and process levels are nowadays still connected by a lot of parallel copper wires but in the near future, as the need for more information exchange increases, these will be replaced by a process bus. A comprehensive set of standards, the IEC61850 series, has been developed to define the requirements for such communication networks and systems in substations [9].

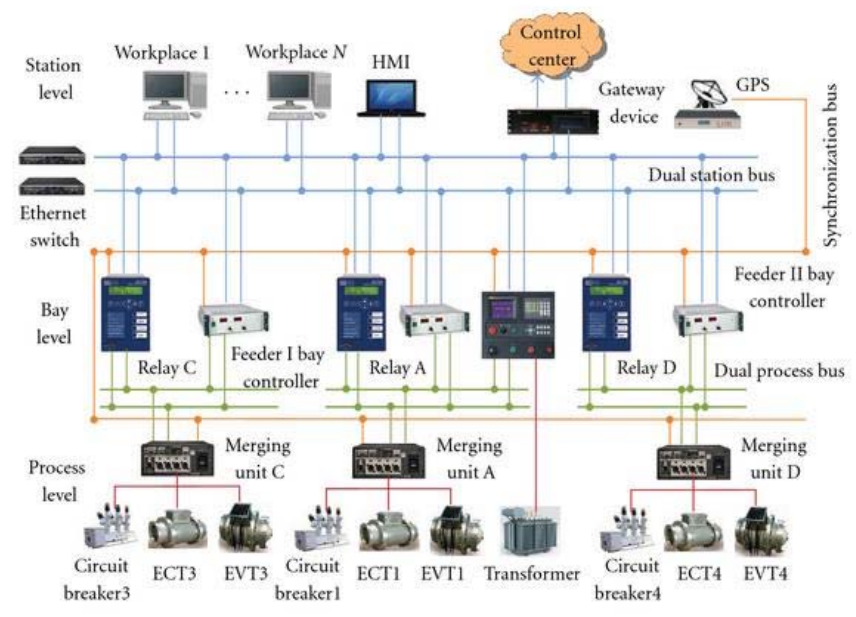

Fig. 1 The system architecture of a substation automation system [8]

Currently, most of the automated substations present a heterogeneous mixture of technologies where the modern IEC61850 structure works in parallel with an analog instrumentation channel serving a relay which will usually actuate an electromechanical protection device.

One of the important elements of an automatic substation is the merging unit (MU) (Fig 1). The merging units are analog to digital data collection devices which sample and digitize electrical quantities. The electrical quantities are analog or digital signals which are of interest. Analog quantities include voltage and current signals from potential transformers (PTs) and current transformers (CTs), transformer temperature signals from resistance temperature detectors (RTDs), transformer turns ratios from potentiometers, etc. Digital quantities include auxiliary contact outputs.

The MUs are placed physically close to the signals which they monitor. This arrangement minimises the potential for signal corruption under normal equipment exploitation. The MUs include usually a weatherised exterior suitable for outdoor and extreme physical conditions common in substations. Although these MUSs are tested to conform to standards such as IEC 60255-25, IEC 60255-22-4 and IEC $61000-4-3$, this may not be enough as field levels than can exist within substations could be larger $[11,14]$ than the ones specified by the above mentioned standards. Therefore, there is a need to develop methodologies and simulation tools that allow prediction and calculation of electromagnetic field emissions in such environments.

\section{SUBSTATION SIMULATION MODEL}

In this research, a specific case of a power substation located in Romania at Rosiori is used. Although at the 
moment this substation is not integrated with IEDs, it will be useful to understand the electromagnetic environment in such a substation prior to installing the IDES.

As the first stage of this study, the substation was modelled using ERACS [17], a power system analysis software. There are several solvers available within ERACS: load flow, fault analysis, harmonic impedance and transient stability solvers. The main aim of this part of the study was to quantify and understand the transient currents that may occur within the substation equipment while different transient phenomena take place.

The substation consists of three outgoing feeders and one compensation coil, together with an autotransformer, at $400 \mathrm{kV}$ and three outgoing feeders on the $220 \mathrm{kV}$ side. The details of the Rosiori 400/220 kV substation components are presented in Table 1 [12].
TABLE I

ROSIORI SUBSTATION COMPONENTS

\begin{tabular}{|l|l|}
\hline \multicolumn{2}{|c|}{ Components of 400kV power station } \\
\hline 1 & Overhead line Gadalin \\
\hline 2 & Overhead line Mukachevo \\
\hline 3 & Overhead line Oradea \\
\hline 4 & $400 \mathrm{MVA}$ Autotransformer 400/220 KV \\
\hline 5 & 100MVAr Reactance coil 400 KV \\
\hline \multicolumn{2}{|c|}{ Component of 220kV power station } \\
\hline 1 & Overhead line Vetis \\
\hline 2 & Overhead line Baia Mare - double circuit \\
\hline
\end{tabular}

The results of the load flow simulation, and then transient stability studies while applying fault at each of the busbars as disturbances within the Rosiori substation, are detailed in the following sections.

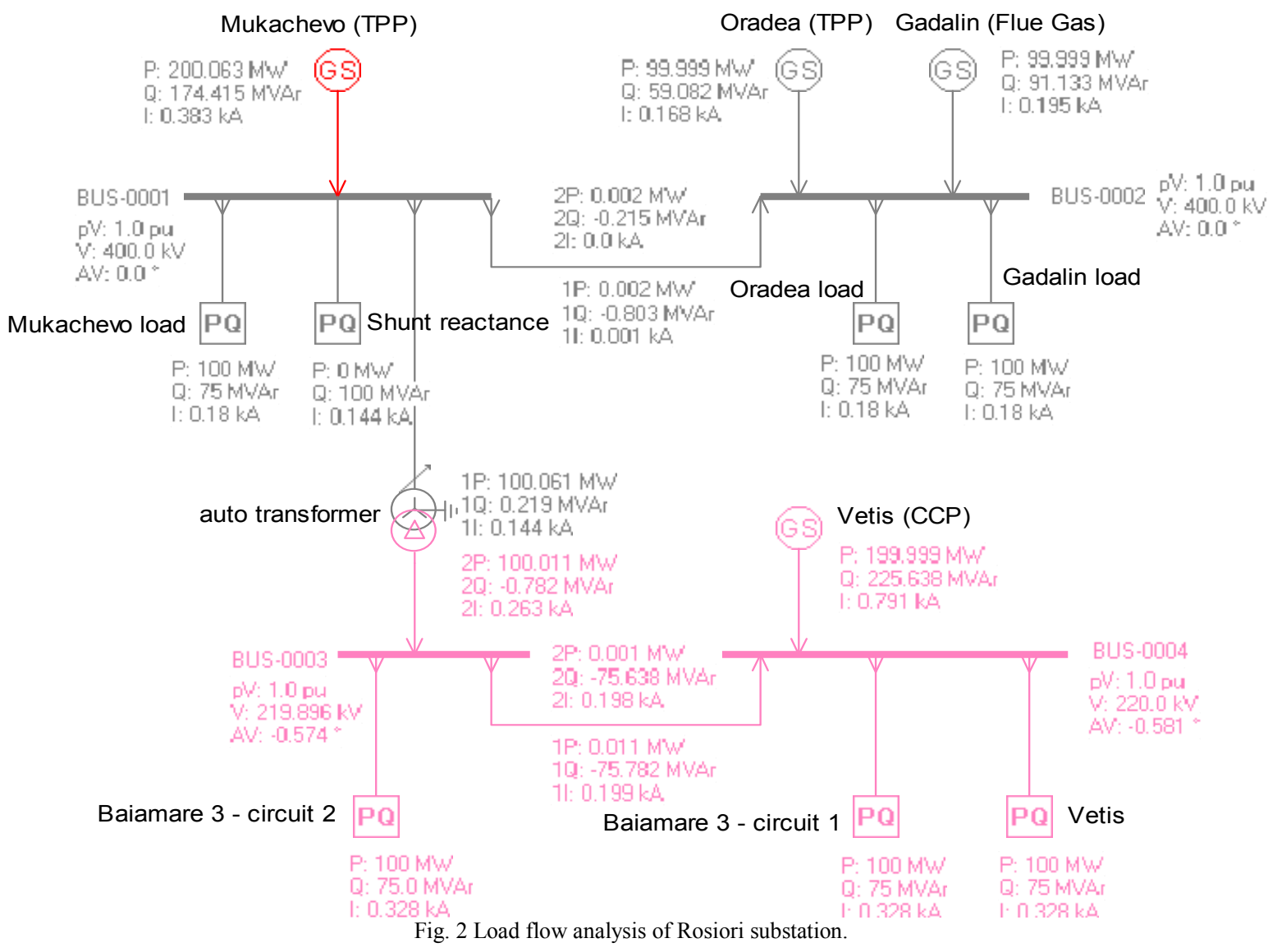

\section{A. Load Flow Analysis}

There are several purposes of load flow analysis, such as to calculate the steady state operation conditions of the power generation or transmission system for a given set of busbar loads; however, for the case under consideration the load flow analysis was necessary for the subsequent transient stability study. The results of the load flow analysis for the Rosiori substation are presented in Fig 2.
Based on the load flow analysis, the total real power generation (PG) is $600.74 \mathrm{MW}$ which is sufficient for real power demand at load (PL) of $600 \mathrm{MW}$. The total generated reactive power (QG) is 564.796MVAr satisfying the necessary reactive power at the load (QL) of 550MVAr. Table II shows the summary of the results of the load flow analysis for the Rosiori substation using ERACS. 
TABLE II

RESULT OF LOAD FLOW ANALYSIS

\begin{tabular}{|c|c|c|}
\hline \multicolumn{3}{|c|}{ Loadflow } \\
\hline $\begin{array}{l}\text { PG: } \\
\text { QG: } \\
\text { PL: } \\
\text { QL: } \\
\text { PLD: } \\
\text { QLD: } \\
\text { Base: } \\
\text { Hz: } \\
\text { PVim: }\end{array}$ & $\begin{array}{l}600.061 \mathrm{WW} \\
550.269 \mathrm{WV} / \mathrm{s} \\
600 \mathrm{WW} \\
550 \mathrm{~W} / \mathrm{Ar} \\
0.061 \mathrm{WW} \\
0.268 \mathrm{~W} / \mathrm{Ar} \\
100 \mathrm{WV} / \mathrm{A} \\
50 \mathrm{~Hz} \\
1.0 \mathrm{pu}\end{array}$ & 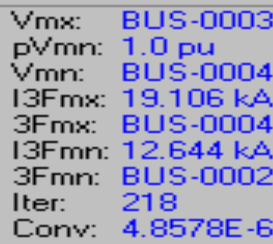 \\
\hline
\end{tabular}

\section{B. Fault Analysis}

Under normal conditions of operation the maximum magnetic field intensity within 400 to $500 \mathrm{kV}$ substations, such as Rosiori, is expected to be between 1.5 to $3 \mathrm{~A} / \mathrm{m}$ [14]. This level of magnetic field intensity should be tolerated by the merging units. However, in the case of a short circuit fault, intensities as high as $160 \mathrm{~A} / \mathrm{m}$ have been reported [14]. Such large magnetic field intensity values can damage electronic equipment such as MUs. To calculate the magnetic field one first has to calculate the fault current. In this work the fault analysis option within ERACS has been used to calculate the fault currents and voltages. The following scenarios have been simulated: a single phase to earth, phase to phase, two phases to earth, and a three phase short circuit fault. These faults are applied at all busbars in the circuit model. The summary of fault analysis results is presented in Table III. The maximum fault current observed for these simulations is when a phase to phase and two phases to earth faults are applied at BUS 3. For these cases the fault current magnitude is $12.306 \mathrm{kA}$.

TABLE III

RESULT OF FAULT ANALYSIS

\begin{tabular}{|l|l|l|l|l|}
\hline \multirow{3}{*}{ Element } & \multicolumn{4}{|c|}{ Fault type (kA) } \\
\cline { 2 - 5 } & $\begin{array}{l}\text { Single phase } \\
\text { to earth (kA) }\end{array}$ & $\begin{array}{l}\text { Phase to } \\
\text { phase (kA) }\end{array}$ & $\begin{array}{l}\text { Two phase to } \\
\text { earth (kA) }\end{array}$ & $\begin{array}{l}\text { Three } \\
\text { phase (kA) }\end{array}$ \\
\hline Busbar 1 & IL1: 10.299 & IL1: 0 & IL1: 0 & IL1: 7.382 \\
& IL2: 0 & IL2: 7.796 & IL2: 8.05 & IL2: 7.382 \\
& IL3: 0 & IL3: 7.796 & IL3: 9.189 & IL3: 7.382 \\
\hline Busbar 2 & IL1: 10.169 & IL1: 0 & IL1: 0 & IL1: 7.378 \\
& IL2: 0 & IL2: 7.783 & IL2: 8.001 & IL2: 7.378 \\
& IL3: 0 & IL3: 7.783 & IL3: 9.108 & IL3: 7.378 \\
\hline Busbar 3 & IL1: 0.001 & IL1: 0 & IL1: 0 & IL1: 11.918 \\
& IL2: 0 & IL2: 12.306 & IL2: 12.306 & IL2: 11.918 \\
& IL3: 0 & IL3: 12.306 & IL3: 12.306 & IL3: 11.918 \\
\hline Busbar 4 & IL1: 0.001 & IL1: 0 & IL1: 0 & IL1: 11.866 \\
& IL2: 0 & IL2: 12.258 & IL2: 12.258 & IL2: 11.866 \\
& IL3: 0 & IL3: 12.258 & IL3: 12.258 & IL3: 11.866 \\
\hline
\end{tabular}

\section{Transient Stability Analysis}

Following the fault analysis a transient stability analysis was undertaken. For such analysis the assumption is that the dynamics of the system is dominated by the transient behaviour of motor loads, generators and governors AVRs. This implies that transmission time delays and distribution network mesh time constants are negligibly small compared with the motor and the generator behaviour [13].

For the Rosiori substation case the results of the transient stability analysis simulations, when a three phase short-circuit fault has been applied to BUS 1, are presented in Fig. 3. The currents in each phase (L1, L2, L3) and the AC and DC components of the fault current are shown. As the data about the four generators connected to the system - Mukachevo, Oradea, Gadalin and Vetis - was not readily available for the transient stability simulation, typical average values of the synchronous-machines constants were assumed [16]. For the above situation the simulation results show that there is a sudden drop in power at $0.05 \mathrm{~s}$; however, the system tries to recover to a stable state. This will result in the oscillating transient state shown graphically in Figs 3, 4 and 5.

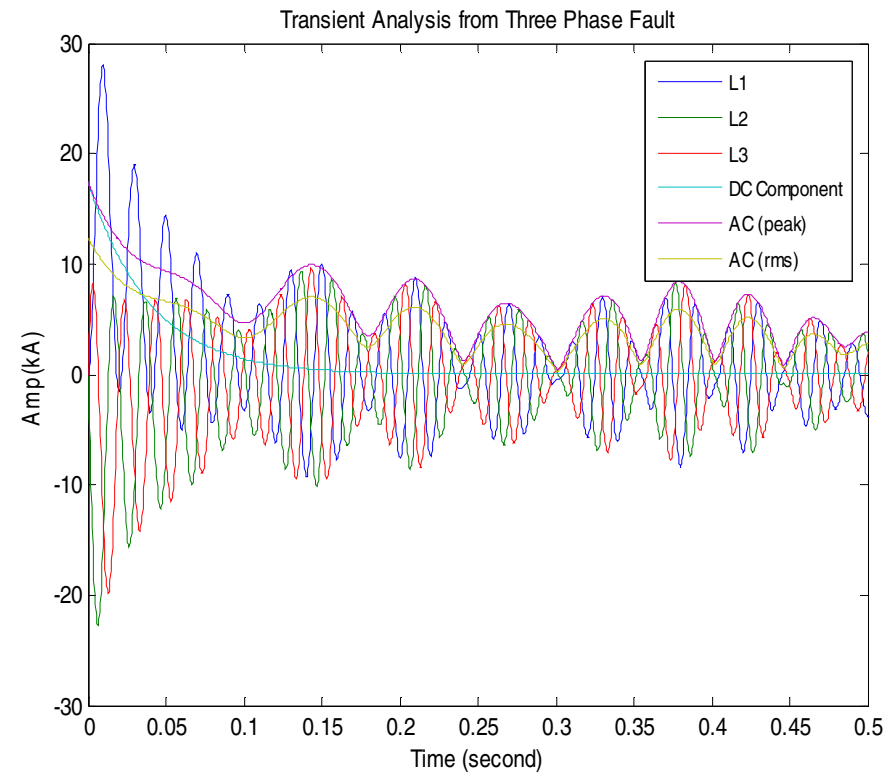

Fig. 3 Transient analysis results due to 3-phase fault at BUS 1.
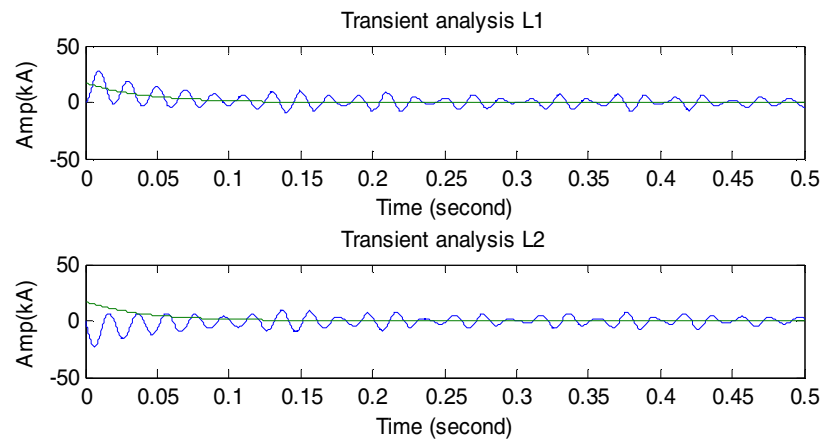

Transient analysis L3

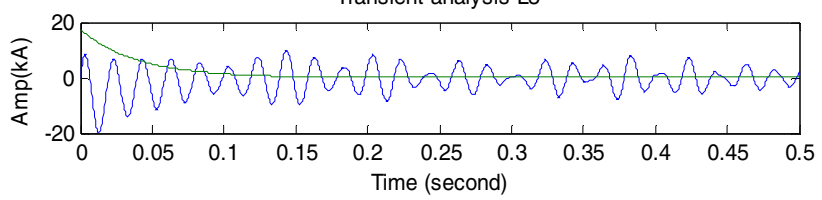

Fig. 4 Transient currents for each of the 3 phase (3phase fault at BUS 1)

From the point of view of the EMC/EMI analysis there is a need to understand not only the magnitude of the fault currents but also their harmonic content. Higher frequency currents are expected to be more detrimental in terms of coupling to other equipment within the substation. A Fast Fourier Technique (FFT) in Matlab was employed to determine the harmonic content of the transient currents obtained from the ERACS simulation. The results of the FFT analysis are summarised below in Fig. 6 . 


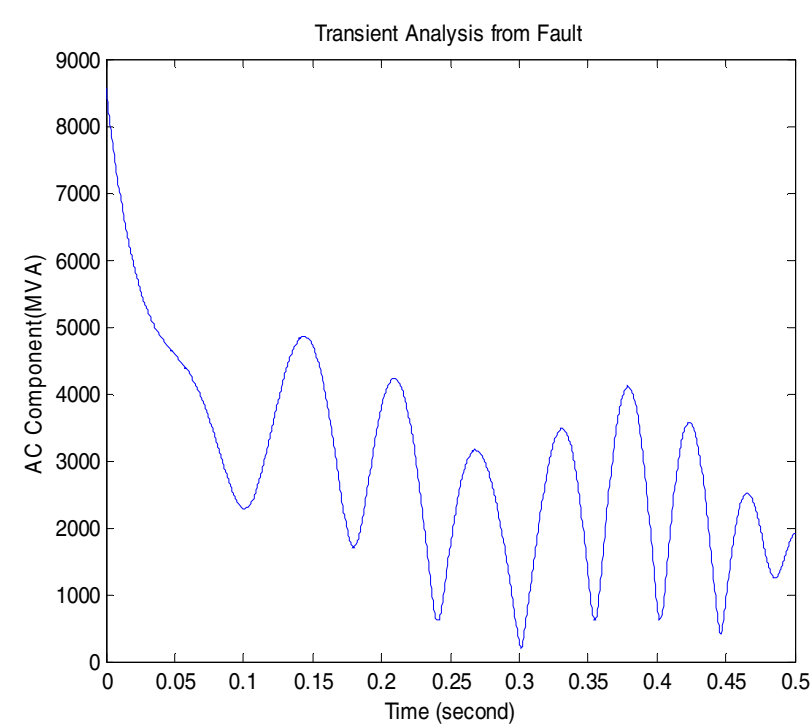

Fig. $5 \mathrm{AC}$ component of the transient power

As shown in Fig. 6 the symmetrical component of the fault currents has the largest magnitude around $6 \mathrm{kA}$ and the same frequency as the fundamental harmonic $(50 \mathrm{~Hz})$. The DC component of the asymmetrical fault currents has smaller amplitude of about $2.8 \mathrm{kA}$.
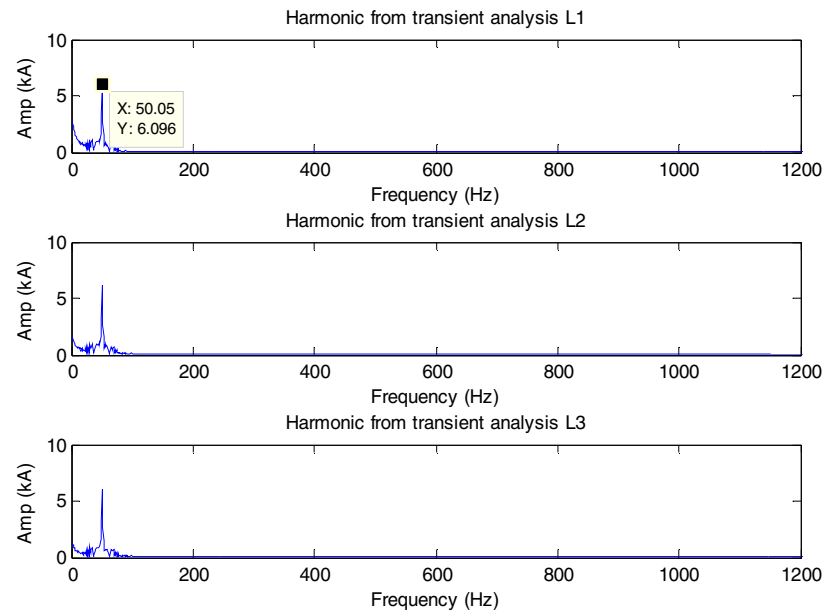

Fig. 6 Harmonic for each phase

It is clear from the results of the FFT analysis that there are no significant higher harmonic currents excited when a transient stability simulation is considered. Hence the only aspect that has to be considered from the EMC/EMI point of view is the magnitude of the currents and their flowing paths within the substation.

\section{CONCLUSIONS AND FUTURE WORK}

Fault current and transient stability simulations of the Rosiori substation were successfully completed using commercial package ERACS. The analysis assumed that the substation is connected to a large grid. The harmonic content of the asymmetrical fault currents calculated by ERACS was determined using the FFT analysis in Matlab. It has been shown that most of the power existent in the transient signal is either DC or the fundamental harmonic $(50 \mathrm{~Hz})$, hence for EMC/EMI analysis the magnitude of the current will be the most important parameter. Going further the results of the transient analysis and fault analysis in terms of currents will be used in the future to excite an electromagnetic model of the Rosiori substation such that the electromagnetic field distributions within the substation will be obtained for these currents. These results will in turn be used to identify the EMI 'hot spots' within the substation. Another aspect that that will be studied is the transient effects when switching of a disconnector or a circuit breakers, especially in the case of inductive loads, takes place. The switching and disconnecting is expected to produce transient currents with much higher harmonic content which may couple significant energy through common-mode currents to electronic equipment installed in the substation switchyard.

\section{REFERENCES}

[1] P. Zhang, F. Li, and N. Bhatt, "Next-generation monitoring, analysis, and control for the future smart control centre," IEEE Trans. Smart Grid, vol. 1, no. 2, pp. 186-192, 2010.

[2] M. Shahraeini, M. H. Javidi, and M. S. Ghazizadeh, "Comparison between communication infrastructures of centralized and decentralized wide area measurement systems," IEEE Trans. Smart Grid, vol. 2, no. 1, pp. 206-211, Mar. 2011.

[3] K. Vu, M. M. Begouic, and D. Novosel, "Grids get smart protection and control," IEEE Comput. Appl. Power, vol. 10, no. 4, pp. 40-44, 1997.

[4] R. Abe, H. Taoka, and D. McQuilkin, "Digital grid: Communicative electrical grids of the future," IEEE Trans. Smart Grid, vol. 2, no. 2, pp. 399-410, Jun. 2011.

[5] L. Fangxing, Q.Wei, S. Hongbin, W. Hui, W. Jianhui, X. Yan, X. Zhao, and Z. Pei, "Smart transmission grid: Vision and framework," IEEE Trans. Smart Grid, vol. 1, no. 2, pp. 168-177, Sep. 2010.

[6] Mhedi Kiani, and Maysam Ghovanloo, "The circuit theory behind coupled-mode magnetic resonance-based wireless power transmission," IEEE Trans. On Circuits and Systems, vol. 59, No. 9, pp. 2065-2074, September 2012

[7] J. Medina, N. Muller, and I. Roytelman, "Demand response and distribution grid operations: Opportunities and challenges," IEEE Trans. Smart Grid, vol. 1, no. 2, pp. 193-198, Sep. 2010.

[8] EMII WG/ Galene Koepke (chair), "Electromagnetic Compatibility and Smart Grid Interoperability Issues" SGIP Electromagnetic Interoperability Issues Working Group, SMART GRID INTEROPERABILITY PANEL SGIP Electromagnetic Interoperability Issues Working Group SGIP Document Number: 2012-005, Version 1.0., December 5, 2012.

[9] Xiang Lu, Wenye Wang, and Jianfeng Ma, " Authentication and Integrity in the Smart Grid: An Empirical Study in Substation Automation Systems," Hindawi Publishing Corporation International Journal of Distributed Sensor Networks Volume 2012, Article ID 175262, 13 pages doi:10.1155/2012/175262.

[10] M. Olofsson, " Power Quality and EMC in Smart Grid," 10th Intenational Conference Electrical Power Quality and Utilisation, 2009.

[11] Claudia Imposimato, Jean Hoeffelman, Anders Eriksson, W.H. Siew, Pieter H. Pretorius and Paul S. Wong " EMI CHARACTERIZATION OF HVAC SUBSTATIONS - UPDATED DATA AND INFLUENCE ON IMMUNITY ASSESSMENT," CIGRE Working Group 36.04, CIGRE 2002.

[12] D. N. FÎTA, L. Muresan, C. Cheleman, and M. Grebenisan, "The Modelling of Rosiori Power Station 400/220/20 KV Retechnologized of Transelectrica Company. The Simulation of the Permanent Regime With EDSA Programme," 6TH International Conference Electromechanical and Power Systems, 2007.

[13] ERA Technology, "Power System Analysis Software -Technical Manual," 2005. 
[14] M. K. Kostin, M. V. Matveye, A. Ovsyannikov, V.S.Verbin and S. Zhivodernikov "SOME RESULTS OF EMC INVESTIGATIONS IN RUSSIAN SUBSTATIONS," 36-103, CIGRE 2002.

[15] J. C. Das, "Transients in Electrical Systems - Analysis, Recognition, and Mitigation" The McGraw-Hill Companies, Inc. 2010
[16] J.D. Glover, M.S. Sarma and T.J. Overbye, "Power System Analysis and Design", Cengage Learning 2011, Fifth ed., SI.

[17] ERACS, http://www.eracs.co.uk/ 